\title{
COMMENTARY
}

\section{From MDGs to SDGs: Implications for Maternal Newborn Health in Africa}

\author{
Sarah M Hodin ${ }^{1}$, Jacquelyn M Caglia ${ }^{2}$, Martina Baye ${ }^{3}$, Joannie Bewa ${ }^{4}$, Peter Waiswa ${ }^{5}$ and Ana \\ Langer ${ }^{6}$
}

Maternal Health Task Force at the Women and Health Initiative, Harvard T.H. Chan School of Public Health ${ }^{1,2,6}$; National Program to combat maternal and child mortality, Ministry of Public Health, Cameroon ${ }^{3}$; Adolescent and Youth Constituency, Partnership for Maternal, Newborn, and Child Health $(\mathrm{PMNCH})^{4}$; Makerere University School of Public Health, Maternal and Newborn Centre of Excellence, Uganda ${ }^{5}$

*For correspondence: Email: jcaglia@ @sph.harvard.edu; Phone: 617-432-7387.

In 2015, the United Nations issued a report detailing the successes and failures of the Millennium Development Goals (MDGs) ${ }^{1}$. Despite some remarkable improvements, a number of targets remain unfulfilled. MDG 5 ambitiously aimed to improve maternal health by reducing the maternal mortality ratio (MMR) by $75 \%$ by lowering the adolescent birth rate and increasing skilled birth attendance, contraceptive usage and antenatal coverage. While very few countries actually achieved this target, we did see a $45 \%$ reduction in the global MMR. As of 2015, the MMR remains highest in sub-Saharan Africa at 546 maternal deaths per 100,000 live births compared to the global MMR of 216 maternal deaths per 100,000 live births ${ }^{2}$. Furthermore, hidden in these global averages are persistent and worsening gaps, as the MMR varies greatly not just between countries but also population groups within them. These inequalities result from a number of factors including disparities in socioeconomic status, unequal access to health care services, and geography.

The 17 Sustainable Development Goals (SDGs) for 2030, adopted at the UN Summit for Sustainable Development in September 2015, call for an increased focus on international partnerships, implementation and measurement, environmental sustainability, solutions that address social injustices and the root causes of poverty $^{3}$. For the maternal newborn health agenda, SDG3 ("ensure healthy lives and promote wellbeing for all at all ages") and SDG5 ("achieve gender equality and empower all women and girls") are perhaps most salient. The ambitious SDG3 targets include reducing the global MMR to no more than 70 maternal deaths per 100,000 live births by 2030, with a supplementary national target that no country should have an MMR greater than 140 per 100,000 live births, and reducing the neonatal mortality rate to no more than 12 infant deaths per 1,000 live births by $2030^{4}$. Difficult social environments for girls and women, low coverage and utilization of antenatal care and skilled birth attendance, and poor quality of care remain major barriers to achieving these targets. In African countries, the percentage of women who receive at least four antenatal care visits per the WHO recommendation is low and variable, ranging from less than $5 \%$ to almost $40 \%{ }^{5}$, with no indication of the content or quality of these clinical encounters when they do occur. Additionally, a wide disparity in skilled birth attendance exists among African countries, with some rates registering at less than $10 \%$ and some more than $90 \%{ }^{5}$.

SDG 5 adds complementary targets to the maternal newborn ones, such as ensuring universal access to sexual and reproductive health and reproductive rights, including access to family planning services, contraceptives, and safe abortion $^{3}$. Access to family planning services and safe abortion is not only a human right, but also a pathway for improving maternal and neonatal health $^{7}$. In 2015, the contraceptive prevalence rate in East and Southern Africa was 38.6\%, and only $17.6 \%$ in West and Central Africa. The adolescent fertility rate in sub-Saharan Africa is more than double that of the world's average ${ }^{5}$, and almost a quarter of women in the region have an unmet need for family planning ${ }^{6}$. Another key SDG5 target is recognizing and valuing women's unpaid 
care and domestic work ${ }^{8}$. Globally, women spend almost $20 \%$ of their time every day doing unpaid work compared to $8 \%$ for men ${ }^{3}$. Furthermore, the wage disparity between men and women reflects gender discrimination and an undervaluing of women's contributions to the health workforce. Women's contributions as both paid and unpaid health care providers are vital to the health of entire communities?

While under the MDGs a number of African countries have had some progress in addressing maternal newborn health issues, further efforts are needed to make the SDGs a reality. In Benin, the MMR decreased from 576 maternal deaths per 100,000 live births in 1990 to 335 deaths per 100,000 live births in 2013, and the infant death rate decreased from 108 deaths per 1,000 live births to 64 deaths per 1,000 live births by $2015^{11,12}$. By $2014,77 \%$ of births were attended by a skilled health professional compared to $64 \%$ of births in $1996^{13}$. Furthermore, caesarean section has been made accessible to more women since it became sponsored by the government in $2009^{14}$. These improvements were driven, in part, by political will as well as the prioritization of maternal health in budgeting. Despite these achievements, Benin has one of the lowest contraceptive prevalence rates in West Africa at about $14 \%$ and a high unmet need for family planning at about $33 \%$,

In a bid to accelerate efforts under the MDGs, the government of Cameroon focused more attention on maternal and child health in terms of investment, strengthening institutional capacity and improving coordination of partners and stakeholders. Between 1990 and 2015, Cameroon saw its MMR decrease from 728 maternal deaths per 100,000 live births to 596 deaths per 100,000 live births and its infant death rate drop from 86 infant deaths per 1,000 live births to 57 deaths per 1,000 live births ${ }^{10,11}$. The national adolescent (15-19 years of age) fertility rate also decreased from 183 births per 1,000 girls in 1990 to 107 births per 1,000 girls in $2014^{17}$. The country, however, has not made much progress toward increasing the rate of skilled birth attendance, which was $60 \%$ in 2000 and $64 \%$ in $2011^{16}$. Furthermore, almost a fourth of women in Cameroon had an unmet need for family planning as of $2011^{5}$.

In Uganda, the MMR decreased from 687 maternal deaths per 100,000 live births in 1990 to 343 deaths per 100,000 live births in 2015, and the infant death rate decreased from 111 infant deaths per 1,000 live births to 38 deaths per 1,000 live births, which resulted in Uganda achieving MDG $4^{10,11}$. Uganda's progress was influenced by the government's free health care policy, a major focus on rolling out high impact child health Interventions and improvements in several social determinants of health. External funding from global initiatives such as USAID, the Global Fund, and GAVI facilitated this progress; however, increased effort is needed to meet the SDGs. According to the most recently available data, only $58 \%$ of births in Uganda are attended by skilled health personnel compared to the average of $68 \%$ in Africa ${ }^{16}$. In terms of family planning, as of 2015, approximately $36 \%$ of women in Uganda have an unmet need for contraception, and a large gap exists between Uganda's family planning goals and its available resources ${ }^{18}$.

Tackling the SDGs will be challenging for many countries in sub-Saharan Africa, as they are starting with the highest burden of disease and often the fewest resources-including limited access to data. Sound measurement and data disaggregation by factors such as sex, gender, socioeconomic status, and area of residence are crucial for identifying the most vulnerable populations, setting priorities, and developing feasible and culturally appropriate interventions to eliminate preventable maternal and newborn deaths and increase access to high quality family planning services. African leaders must invest in the introduction of evidence-based interventions and the data infrastructure needed to improve women and children's health and track outcomes. Achieving the SDGs in Africa will require substantial changes in prioritization, budget allocation, measurement, technical support, and accountability mechanisms. 


\section{Conflict of interest: None}

\section{References}

1. United Nations. The Millennium Development Goals Report 2015. New York. http://www.undp.org /cont ent/dam/undp/library/MDG/English/UNDP_MDG Report2015.pdf.

2. World Health Organization. Trends in Maternal Mortality: 1990-2015 - Estimates by WHO, UNICEF, UNFPA, World Bank Group, and the United Nations Population Fund. 2015. http://apps.who.int/iris/bitstream/10665/194254/1/9 789241565141_eng.pdf?ua=1.

3. United Nations. The Sustainable Development Goals Report 2016. New York. http://unstats.un.org/sdgs/ report/2016/ The\%20Sustainable\%20 Development $\% 20$ Goals\%20Report\%202016.pdf.

4. United Nations. Goal 3: Ensure healthy lives and promote well-being for all at all ages. http://www. un.org/sustainabledevelopment/health/.

5. United Nations Economic Commission for Africa, African Union, African Development Bank Group, UNDP. MDG Report 2015 Lessons Learned in Implementing the MDGs: Assessing Progress in Africa Toward the Millennium Development Goals. 2015.file:///C:/Users/sah770/Downloads/MDG\%20 Report\%202015_ENG.pdf.

6. UNFPA. Universal Access to Reproductive Health: Progress and Challenges. January 2016. http:// www.Unfpa.org/sites/default/files/pubdf/UN FPA_Reproductive_Paper_20160120_online.pdf

7. Ahmed S, et al. Maternal deaths averted by contraceptive use: an analysis of 172 countries. The Lancet 2012; 380(9837): 111-125.

8. United Nations. Goal 5: Achieve gender equality and empower all women and girls. http://www.un.org/ sustainabledevelopment/gender-equality/.

9. Langer A, et al. Women and Health: the key for sustainable development. The Lancet Commissions. June, 2015

10. WHO, UNICEF, UNFPA, World Bank Group, and the United Nations Population Division. Trends in Maternal Mortality: 1990 to 2015. Geneva, World Health Organization, 2015 http://data.World bank.org/indicator/SH.STA.MMRT.

11. Group for Child Mortality Estimation (UNICEF, WHO, World Bank, UN DESA Population Division). Mortality rate, infant (per 1,000 live births) http://data.worldbank.org/indicator/SP.DYN. IMRT.IN?end $=2015 \&$ start $=1990$.

12. Population and Housing Census 2013, Benin INSAE

13. UNICEF, Enquête par grappe à indicateurs multiples, Bénin, MICS, 2014.

14. Système des Nations Unies au Bénin, Rapport d'évaluation des progrès accomplis par le Bénin dans la réalisation des OMD, 2000-2015

15. Family Planning 2020. Benin FP2020 Core Indicator 2014-15 Summary Sheet. http://www.family plann ing 2020.org/ entities/84.

16. UNICEF, State of the World's Children, Childinfo, and Demographic and Health Surveys. Births attended by skilled health staff (\% of total) http://data. World bank.org/indicator/SH.STA.BRTC.ZS?end=2011\&s tart $=2000 \&$ view $=$ chart

17. United Nations Population Division, World Population Prospects. Adolescent fertility rate (births per 1,000 women ages 15-19)http://data.worldbank.org/indic ator/SP.ADO.TFRT?end $=2014$ \&start $=1990$.

18. Family Planning 2020. Uganda FP2020 Core Indicator 2014-15 Summary Sheet. http://www.family planning 2020.org/entities/. 